\title{
Efficacy and Safety of Melphalan, Cyclophosphamide and Dexamethasone (MCD) as a Salvage Treatment for Patients with Relapsed/Refractory Multiple Myeloma
}

\author{
Seung-Shin Lee ${ }^{1}$ and Je-Jung Lee ${ }^{2, *}$ \\ Department of Hematology-Oncology, ${ }^{1}$ Wonkwang University Hospital, Iksan, ${ }^{2}$ Chonnam National University Hwasun Hospital, Hwasun, \\ Korea
}

This study investigated the efficacy and safety of melphalan, cyclophosphamide, and dexamethasone (MCD) as a salvage regimen for heavily treated relapsed or refractory multiple myeloma patients. We retrospectively analyzed a total of 27 patients who received the MCD regimen between April 2011 and November 2013. The MCD regimen consisted of oral melphalan $6.75 \mathrm{mg} / \mathrm{m}^{2}$ on days $1-4$, once-weekly dose of oral cyclophosphamide $300 \mathrm{mg} / \mathrm{m}^{2}$ and dexamethasone $20 \mathrm{mg} / \mathrm{m}^{2}$ on days $1-4$ and days 15-18. Each cycle was repeated every 28 days. The median age of the patients was 66 years and the MCD regimen was initiated at a median 37.7 months from diagnosis. Patients received a median of five regimens including autologous stem cell transplantation. The overall response rate was $25.9 \%$ (very good partial response $3.7 \%$, partial response $22.2 \%)$ and $8(29.6 \%)$ patients achieved a minor response. Median progression-free survival was 5.6 months (95\% confidence interval [CI], 4.2-8.5) ; overall survival 11.7 months (95\% CI, 5.4-16.6). Grade 3 or 4 neutropenia and thrombocytopenia were observed in $51.8 \%$ and $33.3 \%$, respectively. Although the overall response rate is relatively low, the MCD regimen may have a role as a bridge to a novel regimen in heavily pretreated patients with MM.

Key Words: Multiple Myeloma; Salvage Therapy; Melphalan; Cyclophosphamide

This is an Open Access article distributed under the terms of the Creative Commons Attribution Non-Commercial License (http://creativecommons.org/licenses/by-nc/4.0) which permits unrestricted non-commercial use,

distribution, and reproduction in any medium, provided the original work is properly cited.

\section{Article History:}

Received August 24, 2018

Revised October 2, 2018

Accepted October 4, 2018

\section{INTRODUCTION}

Multiple myeloma (MM) is a chronic, malignant disorder of clonal plasma cells characterized by hypercalcemia, anemia, renal insufficiency, and osteolytic bone lesions. The incidence increases with age and the median age of patients at diagnosis is around 65 years. ${ }^{1}$ In the past two decades, the median survival of the MM patients has greatly increased up to more than 10 years with the development of many novel drugs such as proteasome inhibitors, immunomodulatory agents, and monoclonal antibodies. ${ }^{2}$

However, MM is a still incurable disease and all patients who show a good response to initial treatment eventually suffer from disease relapse. With the exception of some patients who have short initial response durations, most patients with disease relapse attain prolonged survival with a salvage treatment which includes a combination of agents with different mechanisms of action and/or improved efficacy. For example, lenalidomide, pomalidomide, carfilzomib, and daratumumab can be used in a relapsed/refractory setting. ${ }^{3-5}$ However, these treatment options are not always available. Although many novel agents are now reimbursed by the national insurance program in Korea, they still can cause an economic burden. Additionally, many approved regimens require frequent hospital visits and hospitalizations. In this context, a favorable salvage treatment needs several virtues such as acceptable efficacy, oral formulation, low price, and minimal safety issues.

The melphalan, cyclophosphamide and dexamethasone (MCD) regimen consists of conventional anti-myeloma drugs. Melphalan, an oral alkylating agent, had been a main drug in combination with prednisone before the era of novel agents. Furthermore, it is still used in higher doses 
as a conditioning regimen for autologous stem cell transplantation (ASCT). ${ }^{6}$ Cyclophosphamide is another alkylator for MM and was used as an induction therapy in combination with thalidomide and dexamethasone in the early 2000 s. ${ }^{7}$ High-dose cyclophosphamide produces a direct toxic effect for cancer cells. In contrast, low-dose cyclophosphamide enhances inhibition of regulatory $\mathrm{T}$ cells which interfere with beneficial immune responses. ${ }^{8}$ Many clinical studies have evaluated its role as an adjunctive treatment to improve response rates and survival. ${ }^{4,9,10}$ Historically, many triplet regimens for MM were comprised of 1 novel agent such as thalidomide, lenalidomide and bortezomib plus corticosteroid plus alkylating agents. Combinations of two alkylators had never been tried. Cyclophosphamide does not show cross-resistance to melphalan. It has a good oral bioavailability and a good safety profile without cumulative hematologic toxicity. ${ }^{10}$ So, the purpose of this study is to investigate efficacy and safety of the MCD regimen as a salvage treatment for previously treated myeloma.

\section{MATERIALS AND METHODS}

We retrospectively analyzed patients who received the MCD regimen from April 2011 and November 2013 for relapsed/refractory MM at a single tertiary center, Chonnam National University Hwasun Hospital, Hwasun, Korea. The patients with AL amyloidosis and/or plasma cell leukemia were excluded. Patients were recruited based on records of chemotherapy prescriptions and their data including characteristics at the diagnosis, previous treatments, treatment responses, toxicities, and survivals were collected using the electronic medical records database. Previous treatments include conventional combination chemotherapies, autologous stem cell transplantation, and novel agents such as bortezomib, thalidomide, lenalidomide.

\section{Treatment and response assessment}

The MCD regimen were repeated every 28 days. Each cycle consisted of oral melphalan $6.75 \mathrm{mg} / \mathrm{m}^{2}$ on D1-4, oral weekly cyclophosphamide $300 \mathrm{mg} / \mathrm{m}^{2}$ and intravenous or oral dexamethasone $20 \mathrm{mg} / \mathrm{m}^{2}$ on D1-4 and D15-18. A melphalan dose reduction of $25 \%$ compared to a conventional dose was chosen based on patients' age and/or tolerability. Dosage and schedule of dexamethasone were modifiable depending on complications such as uncontrolled diabetes, severe asthenia, and/or infectious diseases. The MCD regimen was continued until the occurrence of disease progression, unacceptable toxicities, patient's refusal, or death. If infectious complications developed, the regimen was postponed until full recovery.

The response assessment was done on the first day of the next scheduled cycle. Assessments included measurements of serum and 24-hour urine monoclonal protein, serum free, light chain assay, quantitative involved immunoglobulin assay, and inspection of any new target or- gan damage not otherwise explained. Immunofixation was not performed on each cycle. Response was categorized using the International Myeloma Working Group response criteria $^{11}$; stringent complete response (sCR), complete response (CR), very good partial response (VGPR), partial response (PR), minimal response (MR), stable disease (SD), and progressive disease (PD). The overall response rate (ORR) was defined as a rate of response more than PR. Toxicity was assessed according to the National Cancer Institute Common Terminology Criteria for Adverse Events, version 4.0.

\section{Statistical analyses}

Baseline characteristics, response rate, and toxicity were analyzed using descriptive statistics (median, range and proportions). Progression-free survival (PFS) was defined as the interval from the start day of the MCD regimen to the date of progression or death from any cause and overall survival (OS) and was calculated from the start of the MCD regimen to the date of death from any cause or the final follow-up. The Kaplan-Meier method was used in analyses of PFS and OS. All statistical analyses were conducted by the Statistical Package for the Social Sciences (SPSS) v.21.0 (SPSS Inc., Chicago, IL, USA).

\section{RESULTS}

\section{Patient and treatment characteristics}

Twenty-seven patients who received the MCD regimen were analyzed in this study. Baseline characteristics are described in Table 1 . The median age at MCD was 70 years (range, 49-86). The numbers of patients in ISS stage 2 and 3 were 10 (37\%) and $12(44.4 \%)$, respectively. The ECOG performance status at MCD was no more than 2 in all patients. Among the 15 patients with information on chromosomal abnormalities, 5 patients (33\%) with $14 \mathrm{q} 32$ rearrangement (partner breakpoint not specified) and 3 patients (20\%) with del (13q) were identified by fluorescence in situ hybridization (FISH). Two patients (13\%) were found to have complex karyotypes by conventional cytogenetics. The patients received a median of five regimens (range, 1-12) before MCD including ASCT in 12 patients (44\%), bortezomib in 27 patients (100\%), thalidomide in 25 patients $(93 \%)$, melphalan in 13 patients $(48 \%)$ and lenalidomide in 5 patients (19\%). Twenty-five (93\%) patients were refractory to both bortezomib and thalidomide. All 5 patients (19\%) who had a prior exposure to lenalidomide were pretreated with both bortezomib and thalidomide as well.

The MCD treatment was started at a median interval of 37.7 months (range, 6.0-131.8). The median number of delivered MCD regimens was four (range, 2-15) with 13 patients $(48 \%)$ receiving less than 4 cycles and 14 patients (52\%) 4 cycles or more ; The cause of early therapy discontinuation was disease progression in 5 patients, death from infectious complication (pneumonia, sepsis) without disease progression in 5 patients, follow-up loss in 1 pa- 
tient, patient's refusal in 1 patient, and administration of other treatments in 1 patient.

\section{Efficacy, safety and survival}

Treatment responses are summarized in Table 2. Of the 27 patients treated, seven patients $(25.9 \%)$ achieved more than PR including one VGPR (3.7\%). Minimal response was noted in 8 patients $(29.6 \%)$. In total, the disease control rate (rate of MR or better) of the MCD regimen was found to be $55.5 \%$. Eleven patients $(40.7 \%)$ remained in stable disease. Only one patient had disease progression despite the salvage treatment. Among the subgroups who had an exposure to melphalan, eight patients $(61.6 \%)$ had responses of MR or better. The treatment outcomes of the five patients with a history of lenalidomide treatment was $1 \mathrm{MR}$ and $4 \mathrm{SD}$. Both patients without exposure to immunomodulatory agents achieved PR, but these patients had only one prior regimen. The median cycle of MCD to induce

TABLE 1. Baseline characteristics at MCD treatment

\begin{tabular}{|c|c|}
\hline Characteristics $(\mathrm{n}=27)$ & $\begin{array}{l}\text { Number of } \\
\text { patients }(\%)\end{array}$ \\
\hline Male:Female & $19(70): 8(30)$ \\
\hline Age at diagnosis, median (range), years & $66(46-84)$ \\
\hline Age at MCD treatment, median (range), years & $70(49-86)$ \\
\hline $\begin{array}{l}\text { Intervals between the diagnosis and the MCD } \\
\text { treatment, median (range), months }\end{array}$ & $37.7(6.0-131.8)$ \\
\hline \multicolumn{2}{|l|}{ Subtype } \\
\hline $\operatorname{IgG}$ & $18(67)$ \\
\hline IgA & $6(22)$ \\
\hline Light-chain disease & $3(11)$ \\
\hline \multicolumn{2}{|l|}{ ISS at diagnosis } \\
\hline Stage I & $5(18.6)$ \\
\hline Stage II & $10(37)$ \\
\hline Stage III & $12(44.4)$ \\
\hline \multicolumn{2}{|l|}{ ECOG PS at MCD regimen } \\
\hline 1 & $22(82)$ \\
\hline 2 & $5(18)$ \\
\hline No. of prior treatments, median (range) & $5(1-12)$ \\
\hline Prior autologous stem cell transplantation & $12(44)$ \\
\hline \multicolumn{2}{|l|}{ Prior therapies } \\
\hline Thalidomide & $25(93)$ \\
\hline Lenalidomide & $5(19)$ \\
\hline Bortezomib & $27(100)$ \\
\hline Melphalan & $13(48)$ \\
\hline Bortezomib+Thalidomide & $25(93)$ \\
\hline Bortezomib+Thalidomide+Lenalidomide & $5(19)$ \\
\hline \multicolumn{2}{|l|}{ Chromosomal abnormalities $(\mathrm{n}=15)$} \\
\hline Any abnormality & $8(53)$ \\
\hline 14q32 rearrangement by FISH & $5(33)$ \\
\hline $\operatorname{Del}(13 q)$ by FISH or cytogenetics & $3(20)$ \\
\hline Complex abnormality by cytogenetics & $2(13)$ \\
\hline No abnormality & $7(47)$ \\
\hline
\end{tabular}

ISS: International Staging System, ECOG PS: Eastern Cooperative Oncology Group performance status, FISH: fluorescence in situ hybridization. the lowest serum monoclonal protein (except SD and PD responders) was 5 (range $1-11$ ).

Major toxicity profiles are shown in Table 3. Non-hematologic toxicities reported included nausea, dizziness, diarrhea, and lethargy. These adverse reactions were infrequent and mild. Supportive care alone without treatment delay was sufficient to manage these problems. There was one patient who asked treatment discontinuation due to severe lethargy. Hematologic toxicities were also tolerable. Neutropenia of grade 3 or worse was observed in 14 patients $(51.8 \%)$; anemia in 10 patients $(37 \%)$; and thrombocytopenia in 9 patients (33.3\%). Significant infection defined as one requiring hospitalization developed in ten patients $(37 \%)$.

With the median follow-up duration of 12 months (range, $3-39)$, the median OS of all patients was 11.7 months $(95 \%$ CI, 5.4-16.6) and the median PFS was 5.6 months (95\% CI, 4.2-8.5) (Fig. 1).

\section{DISCUSSION}

Almost all patients with MM may ultimately experience disease relapse. In the last several decades, numerous studies were focused on developing the best salvage treatment. As a result, many combination regimens incorporating proteasome inhibitors, immunomodulatory agents, monoclonal antibodies, and histone deacetylase inhibitors were adopted to improve survival and consistency of recom-

TABLE 2. Response to MCD regimen

\begin{tabular}{lc}
\hline \multicolumn{1}{c}{ Response } & Number of patients $(\%)$, total $\mathrm{n}=27$ \\
\hline Overall response rate & $7(25.9)$ \\
Very good partial response & $1(3.7)$ \\
Partial response & $6(22.2)$ \\
Minimal response & $8(29.6)$ \\
Stable disease & $11(40.7)$ \\
Progressive disease & $1(3.7)$ \\
\hline
\end{tabular}

TABLE 3. Major toxicities associated with MCD treatment

\begin{tabular}{|c|c|c|c|c|c|}
\hline Adverse event & $\begin{array}{c}\text { Grade } \\
1,2\end{array}$ & $\begin{array}{c}\text { Grade } \\
3\end{array}$ & $\begin{array}{c}\text { Grade } \\
4\end{array}$ & $\begin{array}{c}\text { Grade } \\
5\end{array}$ & $\begin{array}{c}\text { Number of } \\
\text { grade } \geq 3 \\
\text { toxicity }(\%) \\
\text { (total } n=27)\end{array}$ \\
\hline Neutropenia & 13 & 8 & 6 & - & $14(51.8)$ \\
\hline Anemia & 17 & 8 & 2 & - & $10(37)$ \\
\hline Thrombocytopenia & 18 & 4 & 5 & - & $9(33.3)$ \\
\hline Significant infection ${ }^{\mathrm{a}}$ & - & 4 & 1 & 5 & $10(37)$ \\
\hline Nausea & 12 & 3 & - & - & $3(11)$ \\
\hline Diarrhea & 6 & - & - & - & - \\
\hline Dizziness & 6 & - & - & - & - \\
\hline Lethargy & 5 & 2 & - & - & $2(7)$ \\
\hline
\end{tabular}

${ }^{\mathrm{a}} 1$ herpes zoster, 1 sepsis, 4 bacterial pneumonias, 1 pneumocystis jirovecii pneumonia, 1 wound infection, 2 urinary tract infection. 
A

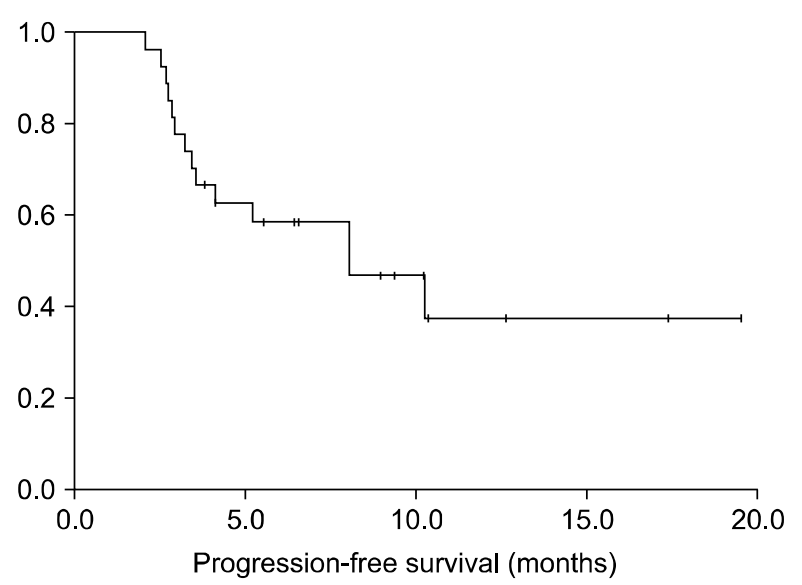

B

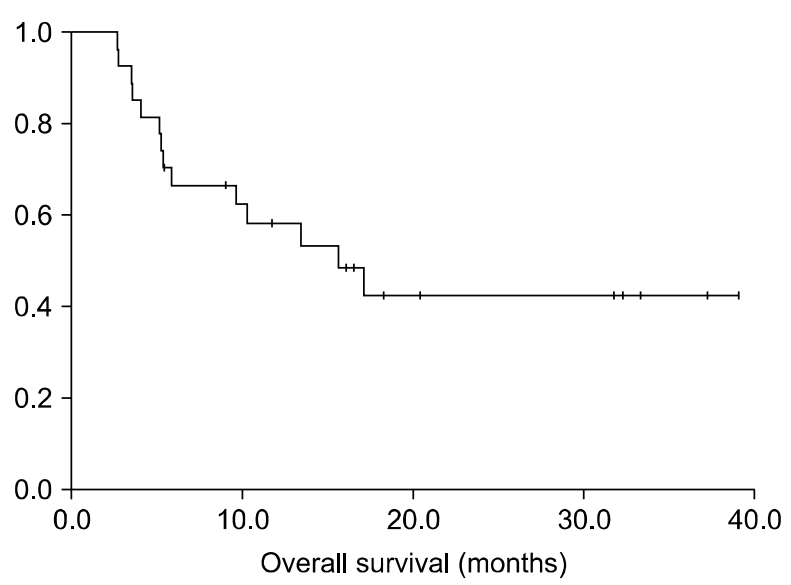

FiG. 1. The Kaplan-Meier curves showing survival outcomes of MCD regimen. (A) Progression-free survival (B) overall survival.

TABLE 4. Literature review of conventional combination chemotherapies for relapsed/refractory myeloma

\begin{tabular}{|c|c|c|c|c|c|c|c|c|c|}
\hline Author, year & $\begin{array}{l}\text { Patient } \\
\text { number }\end{array}$ & $\begin{array}{l}\text { Salvage } \\
\text { regimen }\end{array}$ & $\begin{array}{l}\text { Median } \\
\text { age }\end{array}$ & $\begin{array}{l}\text { ISS stage } \\
\quad 3(\%)\end{array}$ & $\begin{array}{l}\text { Prior } \\
\text { treatment }\end{array}$ & ORR & $\begin{array}{c}\text { PFS } \\
\text { (months) }\end{array}$ & $\begin{array}{c}\text { OS } \\
\text { (months) }\end{array}$ & Safety profile \\
\hline $\begin{array}{l}\text { Dadacaridou M } \\
\text { et al., } 2007^{19}\end{array}$ & $\mathrm{~N}=12$ & DCEP & 58 & N.A. & 2 & $58.3 \%$ & $\begin{array}{l}\text { DoR } 9 \\
\text { months }\end{array}$ & N.A. & $\begin{array}{l}\text { G } 3,4 \text { myelotoxicity(frequency } \\
\text { not reported) }\end{array}$ \\
\hline $\begin{array}{l}\text { Lee CK } \\
\text { et al., } 2003^{17}\end{array}$ & $\mathrm{~N}=236$ & DT-PACE & 60 & N.A. & N.A. & $32 \%$ & N.A. & N.A. & $\begin{array}{l}\text { TRM } 4 \% \text {, } \\
\text { G3,4 neutropenia } 65 \% \\
\text { G3,4 thrombocytopenia } 11 \%\end{array}$ \\
\hline $\begin{array}{l}\text { Damaj G. } \\
\text { et al., } 2012^{22}\end{array}$ & $\mathrm{~N}=110$ & $\mathrm{BP}$ & 63 & $18 \%$ & 4 & $\begin{array}{c}30 \% \\
\text { (CR 2, PR 28) }\end{array}$ & 9.3 & 12.4 & N.A. \\
\hline $\begin{array}{l}\text { Kim SJ et al., } \\
2016^{21}\end{array}$ & $\mathrm{~N}=65$ & $\mathrm{BP}$ & 63 & $54 \%$ & 5 & $35 \%$ & 3.1 & 5.5 & $\begin{array}{l}\text { G3,4 neutropenia } 65 \% \\
\text { G3,4 thrombocytopenia } 46 \%\end{array}$ \\
\hline $\begin{array}{l}\text { Gerrie } \\
\text { et al., } 2013^{18}\end{array}$ & $\mathrm{~N}=75$ & $\mathrm{D}(\mathrm{T})-\mathrm{PACE}$ & 56 & $\begin{array}{l}12 \% \\
\text { unknown } \\
64 \%\end{array}$ & 3 & $\begin{array}{l}49 \% \\
\text { (VGPR } 16, \\
\text { PR33) }\end{array}$ & 5.5 & 14.0 & $\begin{array}{l}\text { TRM 5\%, } \\
\text { G3,4 neutropenia } 88 \% \text {, } \\
\text { G3,4 thrombocytopenia } 69 \%\end{array}$ \\
\hline $\begin{array}{l}\text { Park S. et al., } \\
2014^{20}\end{array}$ & $\mathrm{~N}=59$ & DCEP & 58 & $28.6 \%$ & 3 & $\begin{array}{c}45 \% \\
(\mathrm{CR} 2, \mathrm{VGPR} 2 \\
\text { PR 41) }\end{array}$ & 3.7 & 8.0 & $\begin{array}{l}\text { TRM } 14.8 \% \\
\text { G3,4 neutropenia } 91.5 \% \\
\text { G3,4 thrombocytopenia } 76.3 \%\end{array}$ \\
\hline $\begin{array}{l}\text { Griffin PT } \\
\text { et al., } 2015^{16}\end{array}$ & $\begin{array}{l}\mathrm{N}=52 \\
\mathrm{~N}=22 \\
\mathrm{~N}=33\end{array}$ & $\begin{array}{l}\text { DCEP } \\
\text { VTD-PACE } \\
\text { CVAD }\end{array}$ & $54-57$ & N.A. & 3 & $\begin{array}{l}52 \% \\
73 \% \\
49 \%\end{array}$ & $\begin{array}{l}3.8 \\
4.5 \\
5.8\end{array}$ & $\begin{array}{l}8.9 \\
8.5 \\
8.2\end{array}$ & $\begin{array}{l}\text { TRM 5-9\% } \\
\text { Febrile neutropenia } 29-50 \%\end{array}$ \\
\hline
\end{tabular}

BP: bendamustine and prednisone, CR: complete response, CVAD: cyclophosphamide, vincristine, doxorubicin, and dexamethasone, DCEP: dexamethasone, cyclophosphamide, etoposide and cisplatin, DT-PACE: dexamethasone, thalidomide, cisplatin, doxorubicin, cyclophosphamide and etoposide, DoR: duration of response, G: grade, ISS: International Staging System, N.A.: not available, ORR: overall response rate, PR: partial response, TRM: treatment-related mortality, VGPR: very good partial response, VTD-PACE: bortezomib, thalidomide, dexamethasone, cisplatin, doxorubicin, cyclophosphamide, and etoposide.

mendation by the guidelines. ${ }^{12-14}$ However, a subset of patients with poor prognoses may not have durable responses despite these regimens and need further salvage treatments. Since the choices of salvage treatments for MM are strictly regulated and reimbursed by the national health insurance program in Korea, these heavily pretreated patients eventually have no more options except conventional chemotherapies.

Currently recommended conventional chemotherapeutics used singly or in combination include DCEP (dexamethasone, cyclophosphamide, etoposide and cisplatin), D(T)-PACE (dexamethasone with or without thalidomide, cisplatin, doxorubicin, cyclophosphamide and etopo- side) and bendamustine. ${ }^{15,16}$ Table $4^{16-22}$ demonstrates the results of these regimens. Early in the $2000 \mathrm{~s}$, Lee et al. ${ }^{17}$ first reported the results of 4-day continuous infusion of DT-PACE as a salvage treatment for relapsed myeloma. The cohort of that study is different from ours in that no patient experienced ASCT and the majority of patients did not receive any novel agents. The ORR was $32 \%$ including $16 \% \mathrm{CR}$ or near-CR. Of note, the treatment-related mortality (TRM) developed in $4 \%$ of patients, and neutropenia of grade 3 or 4 developed in $65 \%$ of patients. Prophylactic granulocyte colony-stimulating factor (G-CSF) was routinely administered on day 5 after chemotherapy. In 2007, Gerrie et al. ${ }^{18}$ also examined D(T)-PACE for patients who 
relapsed after treatment with agents (median 3 ) including thalidomide, lenalidomide, bortezomib and carfilzomib. The ORR was $49 \%$ with VGPR of $16 \%$. The TRM was in $5 \%$ of patients. G-CSF was needed in $65 \%$ of cycles for profound neutropenia. The PFS and OS of that population was 5.5 months and 14.0 months, respectively. The DCEP study by Dadacaridou et al. ${ }^{19}$ and Park et al. ${ }^{20}$ showed similar efficacy as that of DT-PACE. Although an acceptable response was noted in their studies, the major concern was hematologic toxicities. In this context, the DCEP and DT-PACE regimens have some drawbacks. Since they are 4-day continuous infusional regimens, patients need multiple peripheral venous lines or central venous catheterization as well as hospitalization for several days. Since hematologic toxicities may be increased with each addition of myelosuppressive agent, frequent blood count monitoring and prolonged hospital stays may be needed and supportive treatments such as blood transfusion, G-CSF administration and prophylactic antibiotics result in high medical expenses.

Bendamustine is a chemotherapeutic wildly used in lymphoid malignancy. Since it has a unique feature of structural similarities to both alkylators and purine analogs, it carries incomplete cross-resistance with cyclophosphamide and melphalan. ${ }^{23}$ Combined with prednisone, bendamustine resulted in an ORR ranging from $30-40 \% .{ }^{21,24}$ In 2016 , a retrospective study by Kim et al. ${ }^{21}$ reported a relatively short PFS and OS (3.1 and 5.5 months, respectively), however this results need to be interpreted carefully because enrolled patients were unselected, more frail, and heavily pretreated.

In our study, the MCD regimen delivered to patients with relapsed/refractory MM resulted in an overall response rate of $25.9 \%$. Although this result may be relatively lower than those of other regimens, the majority of patients attained a response of SD or better. In addition, the PFS and OS benefits from MCD were not inferior to those of other conventional salvage regimens. In terms of toxicity, relatively low incidences of myelosuppression were observed. Other advantages of the MCD is that it could be given orally and on an outpatient basis.

Our study has some limitations. First, a relatively small number of patients was analyzed, so the response rate needs to be confirmed in a study of a larger cohort. Second, because our cohorts had exposure to lenalidomide, response in populations refractory to the newest agents such as pomalidomide, carfilzomib and daratumumab could be lower than reported. Third, our cohort had a relatively good performance status at the time of MCD, they are not representative of real-world population with multiple comorbidities.

In conclusion, the efficacy of a combination regimen of melphalan, cyclophosphamide and dexamethasone is comparable with those of multi-agent infusional regimens as a salvage treatment for heavily pretreated patients with myeloma. Additionally, toxicity profiles of MCD are relatively good and can be easily delivered orally. Considering that MM is ultimately a progressive disease and needs multiple salvage treatments, the MCD regimen has a role as a bridge to newer treatment options.

\section{CONFLICT OF INTEREST STATEMENT}

None declared.

\section{REFERENCES}

1. Dimopoulos M, Spencer A, Attal M, Prince HM, Harousseau JL, Dmoszynska A, et al. Lenalidomide plus dexamethasone for relapsed or refractory multiple myeloma. N Engl J Med 2007;357: 2123-32.

2. Anderson KC. Progress and paradigms in multiple myeloma. Clin Cancer Res 2016;22:5419-27.

3. Zago M, Oehrlein K, Rendl C, Hahn-Ast C, Kanz L, Weisel K. Lenalidomide in relapsed and refractory multiple myeloma disease: feasibility and benefits of long-term treatment. Ann Hematol 2014;93:1993-9.

4. Baz RC, Martin TG 3rd, Lin HY, Zhao X, Shain KH, Cho HJ, et al. Randomized multicenter phase 2 study of pomalidomide, cyclophosphamide, and dexamethasone in relapsed refractory myeloma. Blood 2016;127:2561-8.

5. Usmani SZ, Weiss BM, Plesner T, Bahlis NJ, Belch A, Lonial S, et al. Clinical efficacy of daratumumab monotherapy in patients with heavily pretreated relapsed or refractory multiple myeloma. Blood 2016;128:37-44.

6. Palumbo A, Cavallo F, Gay F, Di Raimondo F, Ben Yehuda D, Petrucci MT, et al. Autologous transplantation and maintenance therapy in multiple myeloma. N Engl J Med 2014;371:895-905.

7. Song MK, Chung JS, Shin HJ, Moon JH, Lee JJ, Yoon SS, et al. Cyclophosphamide-containing regimen (TCD) is superior to melphalan-containing regimen (MPT) in elderly multiple myeloma patients with renal impairment. Ann Hematol 2012;91:889-96.

8. Lutsiak ME, Semnani RT, De Pascalis R, Kashmiri SV, Schlom J, Sabzevari H. Inhibition of CD4(+)25+ T regulatory cell function implicated in enhanced immune response by low-dose cyclophosphamide. Blood 2005;105:2862-8.

9. García-Sanz R, González-Fraile MI, Sierra M, López C, González M, San Miguel JF. The combination of thalidomide, cyclophosphamide and dexamethasone (ThaCyDex) is feasible and can be an option for relapsed/refractory multiple myeloma. Hematol J 2002;3:43-8.

10. Kropff M, Bisping G, Schuck E, Liebisch P, Lang N, Hentrich M, et al. Bortezomib in combination with intermediate-dose dexamethasone and continuous low-dose oral cyclophosphamide for relapsed multiple myeloma. Br J Haematol 2007;138:330-7.

11. Kumar S, Paiva B, Anderson KC, Durie B, Landgren O, Moreau $\mathrm{P}$, et al. International Myeloma Working Group consensus criteria for response and minimal residual disease assessment in multiple myeloma. Lancet Oncol 2016;17:e328-46.

12. Engelhardt M, Terpos E, Kleber M, Gay F, Wäsch R, Morgan G, et al. European Myeloma Network recommendations on the evaluation and treatment of newly diagnosed patients with multiple myeloma. Haematologica 2014;99:232-42.

13. Laubach J, Garderet L, Mahindra A, Gahrton G, Caers J, Sezer 
O, et al. Management of relapsed multiple myeloma: recommendations of the International Myeloma Working Group. Leukemia 2016;30:1005-17.

14. Vincent Rajkumar S. Multiple myeloma: 2014 update on diagnosis, risk-stratification, and management. Am J Hematol 2014; 89:999-1009.

15. National Comprehensive Cancer Network (NCCN). NCCN Clinical Practice Guidelines in Oncology. Multiple Myeloma Version 1. 2019. p.1-78.

16. Griffin PT, Ho VQ, Fulp W, Nishihori T, Shain KH, Alsina M, et al. A comparison of salvage infusional chemotherapy regimens for recurrent/refractory multiple myeloma. Cancer 2015;121:3622-30.

17. Lee CK, Barlogie B, Munshi N, Zangari M, Fassas A, Jacobson J, et al. DTPACE: an effective, novel combination chemotherapy with thalidomide for previously treated patients with myeloma. J Clin Oncol 2003;21:2732-9.

18. Gerrie AS, Mikhael JR, Cheng L, Jiang H, Kukreti V, Panzarella $\mathrm{T}$, et al. D(T)PACE as salvage therapy for aggressive or refractory multiple myeloma. Br J Haematol 2013;161:802-10.

19. Dadacaridou M, Papanicolaou X, Maltesas D, Megalakaki C, Patos P, Panteli K, et al. Dexamethasone, cyclophosphamide, eto- poside and cisplatin (DCEP) for relapsed or refractory multiple myeloma patients. J BUON 2007;12:41-4.

20. Park S, Lee SJ, Jung CW, Jang JH, Kim SJ, Kim WS, et al. DCEP for relapsed or refractory multiple myeloma after therapy with novel agents. Ann Hematol 2014;93:99-105.

21. Kim SJ, Bang SM, Choi YS, Jo DY, Kim JS, Lee H, et al. Bendamustine in heavily pre-treated multiple myeloma patients: results of a retrospective analysis from the Korean Multiple Myeloma Working Party. Blood Res 2016;51:193-9.

22. Damaj G, Malard F, Hulin C, Caillot D, Garidi R, Royer B, et al. Efficacy of bendamustine in relapsed/refractory myeloma patients: results from the French compassionate use program. Leuk Lymphoma 2012;53:632-4.

23. Leoni LM, Bailey B, Reifert J, Bendall HH, Zeller RW, Corbeil J, et al. Bendamustine (Treanda) displays a distinct pattern of cytotoxicity and unique mechanistic features compared with other alkylating agents. Clin Cancer Res 2008;14:309-17.

24. Gentile M, Vigna E, Recchia AG, Morabito L, Mendicino F, Giagnuolo G, et al. Bendamustine in multiple myeloma. Eur J Haematol 2015;95:377-88. 